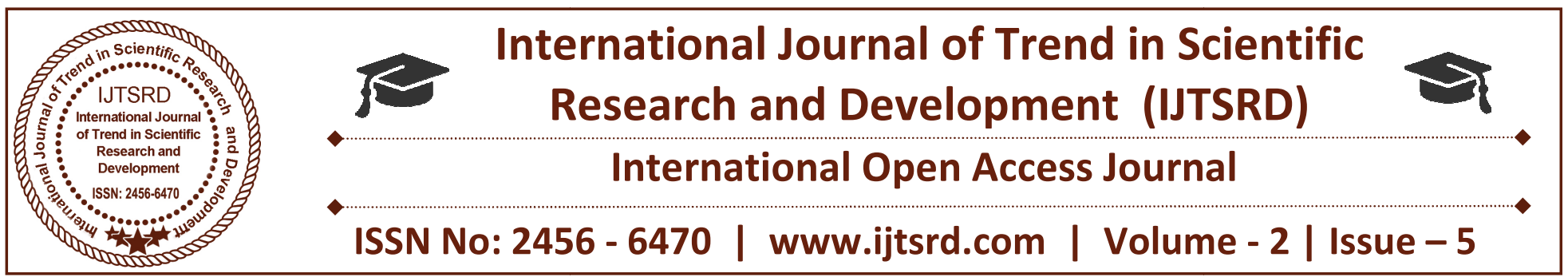

\title{
Innovative Technologies for Electrical Domain
}

\author{
Shajarul Adan ${ }^{1}$, Shavet Sharma ${ }^{2}$ \\ ${ }^{1}$ M.Tech Scholar, ${ }^{2}$ Assistant Professor \\ Department of Electrical Engineering, Sri Sai College of Engineering \& Technology \\ Badhani, Pathankot, Punjab, India
}

\begin{abstract}
Information Technology change the world we live in like connected cars, industries with smart machinery, e-commerce, banking etc. the IOT and Microcontrollers are the most popular technological concepts and have a great importance in Electrical Domain. The paper describes how to deploy latest and emerging technologies in electricity department. The most important advantage is robotic monitoring of power systems like Power Grids, Smart Energy Meters etc. the implementation of GSM technology in electrical department is the most important technical edge.
\end{abstract}

KEYWORD: Sensor, IOT, GSM.

environmentally-safe techniques of gauging utilities consumption so that correct bills can be generated and invoiced. Traditionally, the electricity meters are installed on premises and the consumption information is collected by meter-readers on their fortnightly or monthly visits to the premises. The present era is the era of latest and modern technologies so the smart concept is incorporated in every domain including the electrical department? The implementation of latest technologies in electrical domain resolved number of problems that the department faces during manual billing system.

\section{Communication Interface}

\section{INTRODUCTION}

To send SMS we need communication interface between the energy meter and database server. So we A Smart Grid is a combination of electrical and communication infrastructure using latest technologies of IT within the existing network of electrical engineering through an automated process. As per current scenario the term efficiency is not only the system reliability but also the deployment of Wireless Sensor Networks. Smart Grids are digitally enabled to obtain and distribute information to enhance the reliability, efficiency and sustainability of electrical devices. The energy department needs to send its employees every month in order to take energy meter readings. This is an expensive as well as a time consuming system. The paper describes the use of technologies for electrical department like a more efficient way to get energy meter readings. Electricity is the driving force behind the development of any country. With the rapid increase in residential, commercial, and industrial consumers of electricity throughout the world, it has now become imperative for utilities companies to devise better, non-intrusive,

have two technologies for communication. 1. GSM Network 2. ZIG BEE system. Here we go for GSM network interface because it is best compare the ZIGBEE system because it more sensitive and can easily get affected to the noise in the communication network and data corruption can also takes place. So here go for GSM Network which highly flexible and easy for the transmission in the remote areas. It can also transmit the signal to long distance without any data encryption. GSM (Global System for Mobile Communication): GSM has been the backbone of the phenomenal success of mobile communication in the previous decade. Now at the dawn of true broadband services, GSM continues to evolve to meet new demands. GSM is an open, non-proprietary system with international roaming capability. GSM is a cellular network which means that compatible devices connect to it by searching for cells in the immediate vicinity. There are five different cell sizes in a GSM network via Marco, Micro, Pico, Fenton and Umbrella 
cells. The coverage area of each cell varies according to the Implementation environment. Macro cells can be regarded as cells where base station is installed on a mast or building above roof top level. Micro cells are those in which base station is installed below the average roof top level. These are typically used in the urban areas. Pico cells are the cells whose coverage area is a small and mainly used indoors. Fenton cells are cells designed for use in residential or small business environment and connect to the service provider's network via a broadband internet connection. Umbrella cells are used to cover shadowed reasons of smaller cells and fill in the gaps in coverage between those cells. The modulation used in GSM is Gaussian Minimum Phase Shift Keying (GSMK), a kind of continuous phase frequency shift keying. In GMSK the signal to be modulated on the carrier is first smoothed with a Gaussian low-pass filter prior to being fed into a frequency modulator which greatly reduces the interference to nearby veracity and low-expenses. The using of embedded system improves the stability of wireless data transmission. For a long distance transmission GSM telecommunication has shown excellent performance at any conditions.

\section{The IOT Technology:}

The IOT is rapidly becoming a reality that surrounds us and intersects with many aspects of our lives. Pervasive connectivity and advances in ICT technologies have made possible the connection of more and more devices to the Internet. This is leading to a new wave of applications that have the potential to dramatically improve the way people live, learn, work, and entertain themselves. Sensors play a key role in connecting the physical world (temperature, $\mathrm{CO}_{2}$, light, noise, moisture) with the digital world of IOT. The IOT technology is very important like in solar power plants which need to be monitored for optimum power output. This helps retrieve efficient power output from power plants while monitoring for faulty solar panels, connections, and dust accumulated on panels lowering output and other such issues affecting solar performance.

\section{Sensor Technologies}

We live in an age of relentless and accelerating change, driven by demographic, social, and economic evolution. Each day, there are more of us consuming the finite natural resources of the planet. Our impact on the planet is increasing through urbanization, energy utilization, waste production, and so on, and this impact is not without consequences. Levels of pollution are increasing in our environment, with corresponding effects on our health and well-being. From smog clouds in cities and pollution of our drinking water to simply being denied sufficient peace to sleep soundly at night, human activity has enormous impact on us and on our planet. Major changes in the way we work and live during the last century mean we are also living much more sedentary lifestyles. This has resulted in growing public health issues, such as obesity, arteriosclerosis, cancer, chronic liver disease, and other lifestyle diseases. Increased life expectancy places greater pressures on our healthcare systems as the world's population continues to grow older. Governments are being forced to cut programs such as home healthcare assistance to reduce burgeoning costs. The current model simply does not scale into the future.

Sensors play an integral role in numerous modern industrial applications, including food processing and everyday monitoring of activities such as electricity, transport, air quality, medical therapeutics, and many more. While sensors have been with us for more than a century, modern sensors with integrated information and communications technology (ICT) capabilitiessmart sensors - have been around for little more than three decades. Remarkable progress has been made in computational capabilities, storage, energy management, and a variety of form factors, connectivity options, and software development environments. These advances have occurred in parallel to a significant evolution in sensing capabilities. We have witnessed the emergence of biosensors that are now found in a variety of consumer products, such as tests for pregnancy, cholesterol, allergies, and fertility. We can deploy different types of sensors in our electrical domain also to introduce smartness like ATmega32 with IOT Gecko.

\section{Conclusion:}

In this paper I have briefly described technical aspects for solar power systems. The IOT is the very special technology used to control hardware devices using internet technology. The paper clears the technological aspects that we need to make a dynamic and efficient system. Like implementation of IOT in power grids for remote monitoring, GSM technology for billing process and the most important for the load shedding process. 


\section{REFERENCES:}

1. Abdollahi, A. Dehghani, M. Zamanzadeh,\| SMSbased Reconfigurable Automatic Meter Reading Systemll in Control Applications, 2007.

2. Amin S. Mehmood, T. Choudhry, M. A. Hanif, A -Reviewing the Technical Issues for the Effective Construction of Automatic Meter Reading System\| in International Conference on Microelectronics, 2005 IEEE.

3. Bharath, P.; Ananth, N.; Vijetha, S.; Prakash, K. V. J.; -Wireless Automated Digital Energy Meter\| in Sustainable Energy Technologies, ICSET 2008.

4. Chih-Hung Wu; Shun-Chien Chang; Yu-Wei Huang; -Design of a wireless ARM-based automatic meter reading and control systemll in Power Engineering Society General Meeting, 2004. IEEE.

5. Liting Cao, Jingwen Tian and Dahang Zhang, -Networked Remote Meter-Reading System Based on Wireless Communication Technologyll in International Conference on Information Acquisition, 2006 IEEE.

6. Liting Cao, Wei Jiang, Zhaoli Zhang - Automatic Meter.

7. Dehuaa W, Pana L, Bob L, Zengc G. Water quality automatic monitoring system based on GPRS data communications. Science Direct.2012; 840-3.

8. Detailed Project Report - Intelligent Transport System \& Ethanol Diesel - KSRTC, Mysore. p. 62.

9. Baghyasree T, Janakiraman K, Parkavi D. Efficient remote video monitoring for industrial environment based on LPC2148 and GSM. Indian Journal of Science and Technology. 2014 7(9): 1333-41.

10. Silviya E M, Vinodhini K M, Salai Thillai Thilagam J. GSM Based automatic energy meter system with instant billing. International Journal of Advanced Research in Electrical, Electronics and Instrumentation Engineering. 2014; (3):44-9.

11. Yujun Bao and Xiaoyan Jiang, "Design of electric Energy Meter for long-distance data information transfers which based upon GPRS", ISA 2009. International Workshop on Intelligent Systems and Applications, 2009.
12. H. G. Rodney Tan, C. H. Lee, V. H. Mok, "Automatic power meter reading system using GSM network", The 8th International Power Engineering Conference (IPEC 2007).

13. Vivek Kumar Sehgal, Nitesh Panda, NipunRai Handa, "Electronic Energy Meter with instant billing", UK Sim Fourth European Modelling Symposium on Computer Modelling and Simulation.

14. Bharath P, Ananth N, Vijetha S, JyothiPrakash K. V., "Wireless automated digital Energy Meter", ICSET 2008.

15. P. K. Lee and L. L. Lai, Fieee, "A practical approach to wireless GPRS on-line power quality monitoring system", Power Engineering Society General Meeting, 2007.

16. Subhashis Maitra, "Embedded Energy Meter- A new concept to measure the energy consumed by a consumer and to pay the bill", Power System Technology and IEEE Power India Conference, 2008.

17. T El-Djazairy, B J Beggs and I F Stewart, " Investigation of the use of the Global System for Mobile Communications (GSM) network for metering and load management telemetry", Electricity Distribution. Part 1: Contributions. CIRED.14th International Conference and Exhibition on (IEE Conf. Publ. No. 438).

18. Li Kaicheng, Liu Jianfeng, Yue Congyuan, Zhang Ming. "Remote power management and meter reading system based on ARM microprocessor", Precision Electromagnetic Measurements Digest, 2008.CPEM 2008.Conference on Digital Object Identifier.

19. M. P Praveen, "KSEB to introduce SMS-based fault maintenance system", The Hindu News on 26/06/2011, http://www.hindu.com.

20. Mr. Ankush S. Gutte, Dr. H. K. Naidu, Prof. Pratik Ghutke " Power Meter Billing Plus Load Control using GSM" 2017, International Journal for Research in Applied Science \& Engineering Technology (IJRASET), Volume 5 Issue VIII.

21. PRAVEENKUMAR H S, RAKESH B S, PREETHA P S "GSM Based Automatic Energy Meter Reading with Load Control" 2015, International Journal of Science, Engineering and Technology Research, Volume 4, Issue 5. 
22. Prof. Dr. K. P. Satheyamoorthy "Smart Energy Meter Load Control" 2013, International Journal of Advanced Research in Electrical, Electronics and Instrumentation Engineering, Vol. 2, Issue 8.

23. Mrs. S. H. Shete Mr. V. A. Kulkarni "GSM Enabled Embedded System for Energy Measurement \& Billing” 2013, International Journal of Scientific \& Engineering Research, Volume 4, Issue 1.

24. P. V. Santhoshi Roja, B. Kiran Babu, V. Samson Deva Kumar, Wireless Energy Meter and Billing via 'SMS', 2013, International Journal of Science and Research (IJSR).
27. SarwarShahidi, Md. Abdul Gaffar, Khosru M. Salim, Design \& implementation of Digital Energy Meter with data sending capability using GSM Network, IEEE Conference on Advances 19-21 Dec-2013, Dhaka, Bangladesh.

28. PAV. Loss, M M. Lamego, G. C. D. Sousa, and J. L. F. Vieira. Single phase microcontroller based energy meter. In Conference Record - IEEE Instrumentation and Measurement Technology Conference, volume 2, pages 797-800, 1998. Cited By (since 1996):9.

29. Single-phase power/energy meter with tamper detection. Atmel, page 40, july 2004.

25. H. G.Rodney Tan, C. H. Lee, V. H. Mok, "Automatic Power Meter Reading System Using GSM Network" 2007, IEEE Xplore.

30. T1081CP jfet-input operational amplifires. TEXAS INSTRUMENTATION INCORPORATED, page 45, SEPTEMBER 2004.

26. Paramanand Nayak, Implementation of single phase watt hour meter using LPC2148 thesis paper, NIT Rourkela, May 30, 2013.

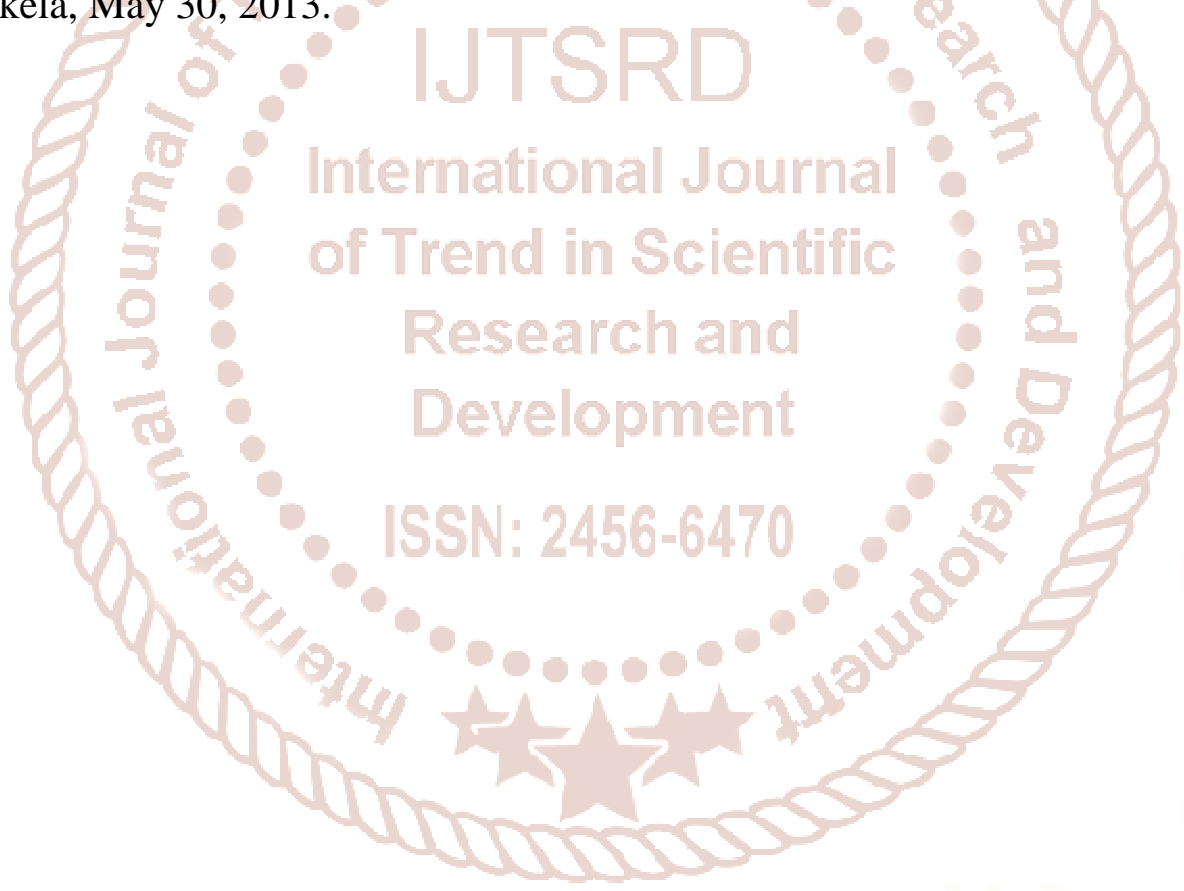

